\title{
Cutaneous Melanoma pT1b TNM Finding v8
}

National Cancer Institute

\section{Source}

National Cancer Institute. Cutaneous Melanoma pT 1b TNM Finding v8. NCI Thesaurus.

Code C136943.

Cutaneous melanoma measuring less than $0.8 \mathrm{~mm}$ in thickness with ulceration, or 0.8-1.0 $\mathrm{mm}$ with or without ulceration. (from AJCC 8th Ed.) 